\title{
Case-Control Study of Alcohol Usage and Fruit Intake and Stomach Cancer in the North Viet Nam
}

\author{
Hoc Hieu Tran', Khanpaseuth Sengngam², Phu Van Pham ${ }^{3}$, Ngoan Tran Le, ${ }^{4 * 5}$
}

\begin{abstract}
Background: The aim was to examine the association between alcohol usage, fruit intake and stomach cancer treated in hospitals in the Hanoi city during 2018-2019. Methods: A case-control study was performed for 379 newly incidence cases of stomach cancer and matched 1096 hospital controls for sex and age (+/-5). We used the validated semi-quantitative food frequency questionnaire to collect data on the intake of alcohol and fruits and other food groups. The average amount of total fruits intake (grams per week) was estimated. The adjusted Odds ratio and $95 \%$ confidence interval (OR $(95 \% \mathrm{CI})$ were estimated. Results: Intake of alcohol significantly increased the risk of stomach cancer, the mean frequency of intake per year of 345.1 times vs. non-drinkers, OR $(95 \% \mathrm{CI}): 1.51(1.05,2.17), p_{\text {trend }}=0.026$. In contrast, a higher total of fruits intake was associated with a significantly decreased risk of stomach cancer in both sexes, men, and women, (Q5 vs Q1), OR (95\%CI): $0.47(0.30,0.72), p_{\text {trend }}=0.000, \mathrm{OR}(95 \% \mathrm{CI}): 0.45(0.26,0.77), p_{\text {trend }}=0.003$, OR $(95 \% \mathrm{CI}): 0.52(0.24,1.12), p_{\text {trend }}=0.026$, respectively. Conclusions: We observed alcohol usage increased the risk of stomach cancers. In contrast, a total of fruits intake was associated with a decreased risk of stomach cancer.
\end{abstract}

Keywords: Stomach cancer- alcohol usage- fruit intake- case-control study

Asian Pac J Cancer Prev, 22 (9), 2903-2908

\section{Introduction}

Viet Nam's population was over 96.2 million on 1 April 2019, national census, ranking $15^{\text {th }}$ most populous country in the world and the third in Southeast Asia. The country is in a sub-tropical region with the main product of agriculture activities and is rich in fruits and vegetables that have been believed to protect against many cancer sites including the stomach. Both fruits and vegetables are rich in micronutrients and contain antioxidants to prevent cancer risks (Chakraborty et al., 2020). Fruits probably protect against stomach cancer (WCRF, 2007). However, only about one third of study participants have a daily intake of fruits and vegetables due to limited knowledge, attitude, and practice of cancer presentation by healthy diet (Falah Asadi et al., 2018). Therefore, more studies on the benefit intake of these organic natural foods are needed. In contrast, the ecological analysis of current by alcohol usage by compared two populations of Japan (high incidence of stomach cancer) and Thailand (low incidence of this cancer) has found that proportion of study participants in Japan (35\%) was significantly higher than in Thailand (2.7\%) (Pittayanon et al., 2018).

Among non-communicable diseases occurrences in
Viet Nam, cancer was the second leading cause of death in 2012 (WHO, 2014; WHO, 2015). Stomach cancer remained important public health that was the third most common cancer incidence in 2018 with an estimated number of $11,161(12.3 \%$ of 164,671 total new cancer cases) (IARC, 2019). There is a lack of information on the association between environmental factors and stomach cancer in the country. We examined the association between alcohol usage, fruit intake and stomach cancer treated in hospitals in Hanoi city during 2018-2019.

\section{Materials and Methods}

A case-control study was conducted for 379 newly incidence cases of stomach cancer and matched 1096 hospital controls for sex and age (+/-5) from three hospitals located in the Hanoi city named Bach Mai, Hanoi Medical University, and National Cancer hospitals, Figure 1.

\section{Case recruitment}

We investigated 379 cases diagnosed having stomach cancer (ICD-10: C16) confirmed by histopathological examination during 2018-2019. Cases were weekly

${ }^{1}$ Department of Surgery, Hanoi Medical University, Hanoi City, Viet Nam. ${ }^{2}$ Department of Occupational Health, Hanoi Medical University, Hanoi City, Viet Nam. ${ }^{3}$ Department of Nutrition and Food Safety, Hanoi Medical University, Hanoi City, Viet Nam. ${ }^{4}$ Institute of Research and Development, Duy Tan University, Da Nang, Viet Nam. ${ }^{5}$ Department of Public Health, School of Medicine, International University of Health and Welfare, Japan.*For Correspondence: letngoan@hmu.edu.vn 
selected from the list of all patients admitted to the Bach Mai, Hanoi Medical University, and National Cancer hospitals for surgical treatment to remove stomach cancer tumors for the first time.

\section{Control recruitment}

We recruited 1096 patients who have admitted been to the same hospital due to the following diseases: kidney donation (18), palm-sweating (8), gall bladder stones (168), benign prostatic hyperplasia (71), hemorrhoids (85), herniation (74), kidney stone (449), stomach polyp (20), and another non-cancer morbidity (203). They have no history of suffering from any cancer in their lifetime.

\section{Exclusion}

Exclusion criteria required for both cancer cases and controls in case they were unable to communicate due to advanced disease stages; patients substantially changing in their diet due to metabolic disorders, and diabetes; and patients refused to participate in the study.

\section{Assessment of alcohol usage and fruit intake}

We used the validated semi-quantitative food frequency questionnaire (SQFFQ) to collect the dietary history of participants in the past year from both cases and controls. The SQFFQ has good characteristics of feasibility, practicaly and reliability in general populations. A strong correlation for energy (adjusted R square $=0.53$ ), moderate correlation for protein (adjusted $\mathrm{R}$ square $=0.38$ ) and carbohydrate (adjusted $\mathrm{R}$ square $=0.36$ ) and small correlation for fat intake (adjusted $\mathrm{R}$ square $=0.20$ ). The SQFFQ included 14 types of fruits and intake of local alcohol products (about 35\% or higher alcohol) among 86 questions to collect data on food frequency of intake. Fruits included Guava common; Sugarapple-sweetsop; Orange; Pomelo; Lemon; Papaya ripe; TangerineMandarin; Banana; Banana-dwarf; Watermelon; Litchilychee; Longan; Jujube; Apple common. A frequency of intake required seven categories: never or less than 6 times a year, 6-11 times/year, 1-3 times/month, 1-2 times/week, 3-4 times/week, 5-6 times/week, and 1-3 times/day. The SQFFQ is designed for online or offline data collection by a smart device using by the trained interviewers. The interviewers collected data by a face-to-face interview, bedside in hospitals.

\section{Data handle and statistical analyses}

The obtained data were exported into both Stata 10 and Excel for double-checking for each record and updated with the final medical records, especially for histopathological confirmation (ICD-10: C16). Body Mass Index (BMI) was calculated as $(\mathrm{BMI}=$ weight $(\mathrm{kg}) /$ height $\left((\mathrm{m})^{2}\right)$ for adjustment.

We estimated the Odds ratio and 95\% confidence interval (OR $(95 \% \mathrm{CI})$ for individual fruit items (higher versus lowest frequency of intake). The adjusted variables included age groups (0-29, 30-39, 40-49, 50-59, 60-69, $\geq 70$ ages), sex, BMI ( 18.5 to $<23,23$ to $<25, \geq 25,<18.5$ ), an education level (Primary school or under, secondary school, high school, higher high school, unknown), and lifetime smoking (yes/no), intake of total fruits (quintiles), intake of total vegetables (quintiles), intake of total meats (quintiles), and intake of total fishes (quintiles).

\section{Ethics consideration}

We submitted the research protocol and received the ethic certificate of approval by the Hanoi Medical University IRB for the present study on 25 Dec. 2018. We obtained written informed consent from all participants of the present study.

\section{Results}

The proportion of men was $71.50 \%$ of stomach cancer (271 of 379 ) and $58.58 \%$ of controls (642 of 1096). About two-thirds of cases aged 50-69. The proportion of obese (BMI $>25$ ) was $4.49 \%$ of cases and $12.59 \%$ of controls, Table 1.

For beverages, there was a null association between a consumption of fresh green tea, drinkers vs nondrinkers, OR $(95 \% \mathrm{CI}): 1.07(0.81,1.41), \mathrm{p}=0.637$; both coffee prepared by machine OR $(95 \% \mathrm{CI}): 0.88(0.62$, $1.25), \mathrm{p}=0.487$ or manual filter OR $(95 \% \mathrm{CI}): 0.83(0.52$, $1.31), p=0.415$, and stomach cancer. Intake of alcohol significantly increased the risk of stomach cancer, the mean frequency of intake per year of 345.1 times vs. non-

Table 1. Characteristics of study participants

\begin{tabular}{|c|c|c|c|c|}
\hline \multirow[t]{2}{*}{ Variables } & \multicolumn{2}{|c|}{ Hospital controls } & \multicolumn{2}{|c|}{ Stomach cancer } \\
\hline & $\mathrm{n}$ & $\%$ & $\mathrm{n}$ & $\%$ \\
\hline \multicolumn{5}{|l|}{ Sex } \\
\hline Men & 642 & 58.58 & 271 & 71.5 \\
\hline Women & 454 & 41.42 & 108 & 28.5 \\
\hline Total & 1,096 & 100.00 & 379 & 100.00 \\
\hline \multicolumn{5}{|l|}{ Age group } \\
\hline $20-29$ & 37 & 3.38 & 2 & 0.53 \\
\hline $30-39$ & 107 & 9.76 & 21 & 5.54 \\
\hline $40-49$ & 221 & 20.16 & 32 & 8.44 \\
\hline $50-59$ & 315 & 28.74 & 122 & 32.19 \\
\hline $60-69$ & 287 & 26.19 & 135 & 35.62 \\
\hline$\geq 70$ & 129 & 11.77 & 67 & 17.68 \\
\hline Total & 1,096 & 100.00 & 379 & 100.00 \\
\hline \multicolumn{5}{|c|}{ Years of schooling } \\
\hline$<6$ & 155 & 14.14 & 66 & 17.41 \\
\hline $6-9$ & 446 & 40.69 & 173 & 45.65 \\
\hline $10-12$ & 316 & 28.83 & 88 & 23.22 \\
\hline$>12$ & 173 & 15.78 & 50 & 13.19 \\
\hline Unknown & 6 & 0.55 & 2 & 0.53 \\
\hline Total & 1,096 & 100.00 & 379 & 100.00 \\
\hline \multicolumn{5}{|l|}{ BMI $\left(\mathrm{kg} / \mathrm{m}^{2}\right)$} \\
\hline $18.5-<23$ & 609 & 55.57 & 190 & 50.13 \\
\hline $23-<25$ & 221 & 20.16 & 32 & 8.44 \\
\hline$\geq 25$ & 138 & 12.59 & 17 & 4.49 \\
\hline$<18.5$ & 109 & 9.95 & 114 & 30.08 \\
\hline Unknown & 19 & 1.73 & 26 & 6.86 \\
\hline Total & 1,096 & 100.00 & 379 & 100.00 \\
\hline
\end{tabular}




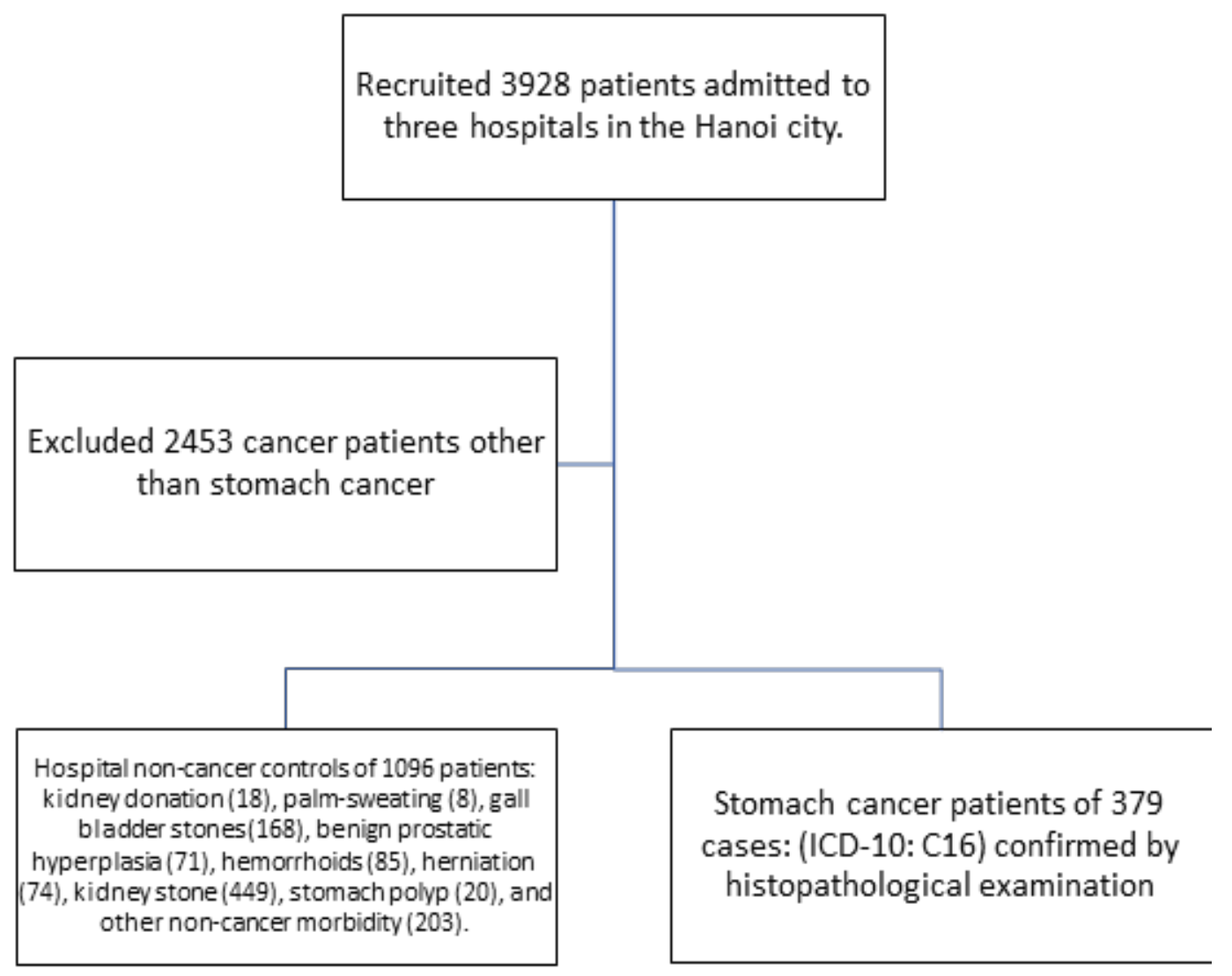

Figure 1. Flow Charge of Study Participants Recruited

drinkers, OR $(95 \% \mathrm{CI}): 1.51(1.05,2.17), p_{\text {_trend }}=0.026$, Table 2.

Among 14 types of fruits, there was a null association between fruits intake and stomach cancer for nine types of fruits (Sugarapple-sweetsop; Orange; Pomelo; Papaya ripe; Tangerine-Mandarin; Watermelon; Litchi-lychee; Longan; and Jujube). High consumption of the other five types of fruits (Guava common; Lemon; Banana; Bananadwarf; and Apple common) was significantly decreased the risk of stomach cancer, Table 3.

The average amount (grams) of total fruits intake per week, men and women combined, was 177.00 (Q1), 379.30 (Q2), 535.30 (Q3), 703.00 (Q4), and 1485.00
(Q5). A higher average amount of total fruits intake per week was associated with a significantly decreased risk of stomach cancer in both sexes, men, and women, (Q5 vs Q1), OR (95\%CI): $0.47(0.30,0.72), p_{\text {trend }}=0.000, \mathrm{OR}$ $(95 \% \mathrm{CI}): 0.45(0.26,0.77), p_{\text {trend }}=0.003$, OR $(95 \% \mathrm{CI})$ : $0.52(0.24,1.12), p_{\text {trend }}=0.026$, respectively, Table 4 .

\section{Discussion}

We observed alcohol usage increased the risk of stomach cancers and in contrast, a total of fruits intake is a strong protective factor against the disease. The findings supported the hypothesis that fruits may decrease the risk

Table 2. Alcohol, Green Tea, and Coffee Intake and Stomach Cancer

\begin{tabular}{|c|c|c|c|c|c|}
\hline Variables & $\begin{array}{l}\text { Frequency of } \\
\text { intake per year }\end{array}$ & $\begin{array}{l}\text { Hospital } \\
\text { controls }\end{array}$ & $\begin{array}{l}\text { Stomach } \\
\text { cancer }\end{array}$ & OR $(95 \% \mathrm{CI}) \$$ & $\mathrm{P}$ \\
\hline \multirow[t]{3}{*}{ Local product of alcohol ( $35 \%$ or higher) } & 1 & 635 & 175 & 1.00 (reference) & \\
\hline & 20.5 & 254 & 95 & $1.27(0.89,1.81)$ & \\
\hline & 345.1 & 207 & 109 & $1.51(1.05,2.17)$ & $0.026 \#$ \\
\hline \multirow[t]{2}{*}{ Fresh green tea } & 1 & 787 & 272 & 1.00 (reference) & \\
\hline & 245.2 & 309 & 107 & $1.07(0.81,1.41)$ & 0.637 \\
\hline \multirow[t]{2}{*}{ Coffee prepared by a machine or bags } & 1 & 901 & 322 & 1.00 (reference) & \\
\hline & 84.9 & 195 & 57 & $0.88(0.62,1.25)$ & 0.487 \\
\hline \multirow[t]{2}{*}{ Coffee prepared by a manual filter } & 1 & 987 & 350 & 1.00 (reference) & \\
\hline & 84.5 & 109 & 29 & $0.83(0.52,1.31)$ & 0.415 \\
\hline
\end{tabular}

\#p for trend; \$Adjusted for age groups (0-29, 30-39, 40-49, 50-59, 60-69, $\geq 70$ ages), sex, BMI (18.5 to $<23,23$ to $<25, \geq 25,<18.5 \mathrm{~kg} / \mathrm{m} 2)$, education level (Primary school or under, secondary school, high school, higher high school, unknown), and lifetime smoking (yes/no), intake of total fruits (quintiles), intake of total vegetables (quintiles), intake of total meats (quintiles), and intake of total fishes (quintiles). 
Table 3. Frequency of Intake of an Individual Fruit per Year and Stomach Cancer

\begin{tabular}{|c|c|c|c|c|c|}
\hline Fruit name (Vietnamese) & Frequency of intake per year & Hospital controls & Stomach cancer & OR $(95 \% \mathrm{CI}) \$$ & $P_{\text {trend }}$ \\
\hline \multirow[t]{3}{*}{ Guava common $(\mathrm{OI})$} & 3.3 & 211 & 153 & 1.00 (reference) & \\
\hline & 24 & 573 & 164 & $0.50(0.37,0.67)$ & \\
\hline & 104 & 312 & 62 & $0.49(0.33,0.73)$ & 0.000 \\
\hline \multirow[t]{3}{*}{ Sugarapple, sweetsop (NA) } & 3.6 & 389 & 199 & 1.00 (reference) & \\
\hline & 24 & 620 & 145 & $0.58(0.44,0.76)$ & \\
\hline & 97.8 & 87 & 35 & $1.63(0.99,2.67)$ & 0.271 \\
\hline \multirow[t]{3}{*}{ Orange (CAM) } & 17 & 725 & 232 & 1.00 (reference) & \\
\hline & 78 & 296 & 108 & $1.47(0.87,2.48)$ & \\
\hline & 262.3 & 75 & 39 & $1.12(0.41,3.05)$ & 0.321 \\
\hline \multirow[t]{2}{*}{ Pomelo (BUOI) } & 16.7 & 886 & 310 & 1.00 (reference) & \\
\hline & 154.8 & 210 & 69 & $1.13(0.58,2.20)$ & - \\
\hline \multirow[t]{3}{*}{ Lemon (CHANH) } & 2.5 & 265 & 159 & 1.00 (reference) & \\
\hline & 24 & 361 & 113 & $0.61(0.45,0.84)$ & \\
\hline & 230 & 470 & 107 & $0.55(0.39,0.76)$ & 0.000 \\
\hline \multirow[t]{3}{*}{ Papaya ripe (DU DU) } & 3.7 & 515 & 202 & 1.00 (reference) & \\
\hline & 24 & 455 & 153 & $0.98(0.74,1.29)$ & \\
\hline & 104.9 & 126 & 24 & $0.92(0.53,1.58)$ & 0.779 \\
\hline \multirow[t]{3}{*}{ Tangerine (QUIT) } & 1 & 189 & 132 & 1.00 (reference) & \\
\hline & 20.7 & 767 & 196 & $0.45(0.33,0.61)$ & \\
\hline & 108.1 & 140 & 51 & $1.06(0.66,1.69)$ & 0.070 \\
\hline \multirow[t]{3}{*}{ Banana (CHUOI TA) } & 2.7 & 233 & 154 & 1.00 (reference) & \\
\hline & 24 & 483 & 156 & $0.53(0.39,0.71)$ & \\
\hline & 142.3 & 380 & 69 & $0.38(0.25,0.57)$ & 0.000 \\
\hline \multirow{3}{*}{$\begin{array}{l}\text { Banana, dwarf } \\
\text { (CHUOI TIEU) }\end{array}$} & 2.5 & 256 & 168 & 1.00 (reference) & \\
\hline & 24 & 464 & 142 & $0.54(0.40,0.72)$ & \\
\hline & 142.8 & 376 & 69 & $0.39(0.26,0.59)$ & 0.000 \\
\hline \multirow[t]{3}{*}{ Watermelon (DUA HAU) } & 3 & 300 & 180 & 1.00 (reference) & \\
\hline & 24 & 649 & 157 & $0.54(0.40,0.73)$ & \\
\hline & 105.1 & 147 & 42 & $1.09(0.65,1.84)$ & 0.077 \\
\hline \multirow[t]{3}{*}{ Litchi; lychee (VAI) } & 3.7 & 340 & 190 & 1.00 (reference) & \\
\hline & 24 & 679 & 169 & $0.66(0.50,0.87)$ & \\
\hline & 107.5 & 77 & 20 & $1.14(0.62,2.11)$ & 0.068 \\
\hline \multirow[t]{3}{*}{ Longan (NHAN) } & 3.8 & 341 & 182 & 1.00 (reference) & \\
\hline & 24 & 690 & 169 & $0.69(0.52,0.91)$ & \\
\hline & 106.3 & 65 & 28 & $2.24(1.26,3.98)$ & 0.767 \\
\hline \multirow[t]{3}{*}{ Jujube (TAO TA) } & 1 & 262 & 148 & 1.00 (reference) & \\
\hline & 19.3 & 772 & 204 & $0.61(0.46,0.81)$ & \\
\hline & 105.1 & 62 & 27 & $1.76(0.99,3.13)$ & 0.207 \\
\hline \multirow[t]{3}{*}{ Apple common (TAO TAY) } & 1 & 352 & 209 & 1.00 (reference) & \\
\hline & 19.4 & 624 & 134 & $0.38(0.29,0.51)$ & \\
\hline & 93.9 & 120 & 36 & $0.84(0.53,1.34)$ & 0.000 \\
\hline
\end{tabular}

\$Adjusted for age groups (0-29, 30-39, 40-49, 50-59, 60-69, $\geq 70$ ages), sex, BMI (18.5 to $<23,23$ to $\left.<25, \geq 25,<18.5 \mathrm{~kg} / \mathrm{m}^{2}\right)$, education level (Primary school or under, secondary school, high school, higher high school, unknown), and lifetime smoking (yes/no), intake of total fruits (quintiles), intake of total vegetables (quintiles), intake of total meats (quintiles), and intake of total fishes (quintiles).

of gastric cardia cancers (Vingeliene et al., 2016) and the conclusion of "Fruits probably protect against stomach cancer" by the World Cancer Research Fund/American Institute for Cancer Research (WCRF, 2007). The results were also consistent with the recent conclusions on the inverse association between fruit intake and stomach cancer (Bae and Kim, 2016; Foschi et al., 2010; Gonzalez et al., 2012; Steevens et al., 2011).

Fruits are rich in vitamins, minerals, and other bioactive compounds that may protect against cancers: 
Table 4. Total Fruit Intake and Stomach Cancer by Sex

\begin{tabular}{lcccc}
\hline Total fruits intake, mean (grams) per week & Hospital controls & Stomach cancer & OR $(95 \% \mathrm{CI}) \$$ & $p_{\text {trend }}$ \\
\hline Both sexes & & & \\
177 & 156 & 139 & 1.00 (reference) \\
379.3 & 220 & 75 & $0.43(0.29,0.62)$ \\
535.3 & 246 & 49 & $0.28(0.18,0.42)$ \\
703 & 235 & 60 & $0.39(0.26,0.58)$ & 0.000 \\
1485 & 239 & 56 & $0.47(0.30,0.72)$ & \\
Men & & & & \\
170 & 101 & 97 & $1.00($ reference $)$ \\
378 & 140 & 53 & $0.42(0.27,0.65)$ \\
532.9 & 150 & 37 & $0.29(0.18,0.47)$ \\
705.3 & 129 & 46 & $0.44(0.27,0.72)$ \\
1560.7 & 122 & 38 & $0.45(0.26,0.77)$ & 0.003 \\
Women & & & & \\
191.2 & 55 & 42 & $1.00($ reference $)$ \\
381.9 & 80 & 22 & $0.46(0.23,0.90)$ \\
539.4 & 96 & 12 & $0.25(0.12,0.55)$ \\
699.6 & 106 & 14 & $0.29(0.14,0.63)$ \\
1395.2 & 117 & 18 & $0.52(0.24,1.12)$ \\
\hline
\end{tabular}

\$Adjusted for age groups $\left(0-29,30-39,40-49,50-59,60-69, \geq 70\right.$ ages), sex, BMI $\left(18.5\right.$ to $<23,23$ to $\left.<25, \geq 25,<18.5 \mathrm{~kg} / \mathrm{m}^{2}\right)$, education level (Primary school or under, secondary school, high school, higher high school, unknown), and lifetime smoking (yes/no), intake of total fruits (quintiles), intake of total vegetables (quintiles), intake of total meats (quintiles), and intake of total fishes (quintiles).

"Fruits in general probably protect against cancers of the mouth, pharynx, and larynx, and those of the esophagus, lung, and stomach" (WCRF, 2007).

For alcohol intake, our findings are consistent with some Meta-analyses and an investigation of the mechanisms of alcohol-induced stomach cancer (Han et al., 2017; He et al., 2017; Ma et al., 2017; Na and Lee, 2017; Rota et al., 2017). Alcohol promotes the uptake of carcinogens and their metabolism to induce stomach cancer.

The findings are timely in Viet Nam because the country is located in a sub-tropical region where farm products of fruits are common during four seasons (spring, summer, autumn, and winter) in the North and two seasons (rainy and dry) in the South. With the rapid development of the economy, transportation, refrigerator available at home, people would have more chances to consume daily fruits in general and citrus fruits, in particular, to prevent the occurrence of stomach cancer. To achieve this goal, a program of health education of a healthy diet that in rich in fruits, vegetables, and reduces harmful usage of alcohol is highly recommended and needed.

The limitation of this case-control study was that the status of H. Pylori infection and tumor location in the stomach and types of cancer cells were not available. The spite these limitations, the findings will add new evidence of the harmful usage of alcohol-induced stomach cancer in our study population in a middle-income country. Because the country is located in a sub-tropical region, where farm productions of fruits are common and people have in their hands the means to lead healthy diets, fuller, healthier lives

\section{Author Contribution Statement}

None.

\section{Acknowledgements}

Research Grant Agreement: 18/FIRST/1a/HMU, Under the Project: "Fostering Innovation through Research, Science and Technology".

\section{Conflict of interest}

There are no conflicts to disclose

\section{References}

Bae JM, Kim EH (2016). Dietary intakes of citrus fruit and risk of gastric cancer incidence: an adaptive meta-analysis of cohort studies. Epidemiol Health, 38, e2016034.

Chakraborty A, Guha S, Chakraborty D (2020). Micronutrients in preventing cancer: A Critical Review of Research. Asian Pac J Cancer Biol, 5, 119-25.

Falah Asadi A, Shahsavari S, Khosravizadeh O, Nourmohammadi M (2018). The relationship between knowledge, attitude, and performance in breast cancer with nutritional behaviors and drug use. Asian Pac J Environ Cancer, 1, 27-33.

Foschi R, Pelucchi C, Dal Maso L, et al (2010). Citrus fruit and cancer risk in a network of case-control studies. Cancer Causes Control, 21, 237-42.

Gonzalez CA, Lujan-Barroso L, Bueno-de-Mesquita HB, et al (2012). Fruit and vegetable intake and the risk of gastric adenocarcinoma: a reanalysis of the European Prospective Investigation into Cancer and Nutrition (EPIC-EURGAST) study after a longer follow-up. Int J Cancer, 131, 2910-9.

Han X, Xiao L, Yu Y, Chen Y, Shu HH (2017). Alcohol consumption and gastric cancer risk: a meta-analysis of 
prospective cohort studies. Oncotarget, 8, 83237-45.

He Z, Zhao TT, Xu HM, et al (2017). Association between alcohol consumption and the risk of gastric cancer: a meta-analysis of prospective cohort studies. Oncotarget, 8, 84459-72.

IARC (2019). International Agency for Research on Cancer: Globocan 2018 - Viet Nam: Lyon, France.

Ma K, Baloch Z, He TT, Xia X (2017). Alcohol consumption and gastric cancer risk: A Meta-Analysis. Med Sci Monit, 23, 238-46.

Na HK, Lee JY (2017). Molecular basis of alcohol-related gastric and colon cancer. Int J Mol Sci, 18.

Pittayanon R, Uedo N, Praipisut T, et al (2018). Factors associated with high mortality of gastric adenocarcinoma in Thailand Versus Japan. Asian Pac J Cancer Care, 3, 29-35.

Rota M, Pelucchi C, Bertuccio P, et al (2017). Alcohol consumption and gastric cancer risk-A pooled analysis within the StoP project consortium. Int J Cancer, 141, 1950-62.

Steevens J, Schouten LJ, Goldbohm RA, van den Brandt PA (2011). Vegetables and fruits consumption and risk of esophageal and gastric cancer subtypes in the Netherlands Cohort Study. Int J Cancer, 129, 2681-93.

Vingeliene S, Chan DS, Aune D, et al (2016). An update of the WCRF/AICR systematic literature review on esophageal and gastric cancers and citrus fruits intake. Cancer Causes Control, 27, 837-51.

WCRF (2007). Food, Nutrition, Physical Activity, and the Prevention of Cancer: a Global Perspective. World Cancer Research Fund / American Institute for Cancer Research: Washington DC AICR.

WHO (2014). Global status report on noncommunicable diseases 2014: "Attaining the nine global noncommunicable diseases targets; a shared responsibility. World Health Organization: Geneva, Switzerland.

WHO (2015). Non-communicable Diseases Progress Monitor 2015. Publication date: September 2015. ISBN: 97892 4150945 9. http://www.who.int/nmh/publications/ncdprogress-monitor-2015/en/. World Health Organization: Geneva, Switzerland.

\section{c) (7) (8)}

This work is licensed under a Creative Commons AttributionNon Commercial 4.0 International License. 